\section{ORIGRTAL COMAUUTHCATIONS.}

\section{CONTINUED FEVER IN CHILDREN.}

By WILLIAM JOHN ANDERSON, F.R.C.S., Accoucheur to the St. George's and St. James's Dispensary.

[Read before the Harveian Society.]

Ix systematic works upon the diseases of children, we find little or no mention made of continued fever; not that this complaint is essentially an infantile one, far from it; but many other affections equally common to the adult as well as to the child, have been copicusly described in such treatises, while this has been altogether omitted. The diagnosis in such cases is important, not only as affecting the patient with regard to appropriate treatment, but also as concerning the safety of others, by giving them timely warning to aroid contagion as much as possible. The contagious nature of continued fever has been denied by some: I am, however, a staunch contagionist, and, being such, am fully persuaded that the disease may be propagated with the same degree of certainty by a child as by an adult. In June 1853, I saw a striking illustration of this, which it may not be out of place to mention here. A child, not quite four years old, came under my care with a severe attack of continued fever, complicated with head symptoms. This child recovered, but her mother now became affected; and gix other children had it likewise. Now, it might be urged that this was endemic; that some local cause, which had produced the disease in the first child, had also caused it in the other members of the family. This argument might hold good possibly with the mother, but not with the other children; for they removed to a totally different locality before they were affected, the mother alone having shown incipient symptoms previous to their change of abode.

It is not my intention to enter into a detailed account of the symptoms of continued fever. Every medical man is so perfectly conversant with them, and they have been so frequently and ably described by eminent practitioners, that it would be superfluous to attempt it. The fever in the child does, in no material point, differ from that which occurs in the adult; the only thing to be borne in mind is the difference of age and constitution. We must remember that this complaint, which will at once strike down the hale strong man, and render him as helpless as the new-born babe, has now to be dealt with in a little fragile being, in whom any complication may speedily run on to a fatal end, or leave permanent injury behind it. Bearing this in mind, we must see the necessity for extreme watchfulness on our part; and I need scarcely add, that the tender age of our little patients must always, in a right feeling mind, induce that sympathy and interest, which will excite the greatest energy in their behalf.

The continued fever of children may, for the convenience of description, be divided into three heads, viz. : First, simple uncomplicated continued fever; secondly, continued fever, aggravated with complications; thirdly, continued fever, commencing in the first instance with remittent symptoms.

With regard to the two first of these divisions, very little need be said, beyond bringing forward some illustrative cases, with a few passing remarks, which will perhaps serve better to show their nature, than any detailed accounts alone could possibly do.

SIMPLE UNCOMPLICATED CONTINUED FEVER.

This is of course the mildest and most tractable form, not differing in any respect from the continued fever of adults, with the exception, as before stated, of its occurring in a child, whose tender age renders it less capable of bearing up against a serere illnoss of such a description. The treatment must of course be palliative, not curative; for there is a good old maxim, which all know well by experience, "we may guide a ferer, but we cannot cure it".

CAsE I. Henry T., aged 3 years, Feb. 8th, 1853, had been attacked five day before with shirering followed by heat, and was reported to have wandered much on two successive nights. He was then fererish and thirsty, with dry heat of skin, slight hacking cough, but no stethoscopic signs. Pulso 136 ; tongue dry and brown; bowels confined.

R. Iiqnoria ammoniæe acetatis $3 i j$, Spiritûs ætheris nitrosi $\mathbf{m} \times \mathbf{x}$, Nisturæ camphoræ $3 \mathrm{rj}$.

Fiat haustus sextis horis sumendus.

R Hydrargyrum cum cretâ gr. iij.

Fiat pulvis statim sumendus.

$R$ Olei ricini 3 iss.

Post horas ij.

Feb. 9th. The bowels had not acted; in other respects he was much the same. Repetatur oleum ricini.

Feb. 10th. Bowels still unrelieved, in consequence of the stomach rejecting the oil; tongue dry and brown; pulse 120. Ad sedes.

R Haustûs sennæ $\zeta$ ss.

Feb. 11th. Bowels had acted freely; tongue cleaner and moister; pulse 130 ; skin less dry.

Feb. 12th. Much better in every respect. Pulse 112; skin moister; tongue cleaner.

Feb. 17th. The tongue was perfectly clean; skin moist; pulse 100. He now improved rapidly, and was perfectly well by the 10th March.

CASE II. Anne A., aged 5. Nov. 28th, 1853. Was attacked a day before with shivering followed by dry heat, which continued on and off to the time I saw her. The child was then shivering; there was much anxicty of countenance; complexion sallow; breathing rapid and gasping; slight cough; tongue foul and loaded; pulse 130 , of tolerable strength; chest resonaut on percussion; heart's action much increased; respiration spasmodic, but otherwise natural. This patient had recently been attended by myself for an attack of scarlatina.

B Liquoris ammonix acetatis $3 \mathrm{ij}$,

Spiritús ætheris nitrosi $3 \mathrm{ss}$, Misture camphorx 3 ri. M.

Fiat haustus sextis horis sumendus.

R Hydrargyri cum cretâ gr. iij.

Horâ noctis sumatur.

Nor. 29th. Much the same. Bowels confined.

$\mathrm{B}$ Olei ricini $3 \mathrm{ij}$.

Statim sumatur.

Nov. 30th. Pulse 120; tongue foul; wandered at night slightly; scemed drowsy, and complained of headache; but there was very little heat of scalp. Repeat the mixture. Repeat the powder at bedtime.

Dec. 4th. There had been no material difference in the symptoms until this day. The tongue was now somewhat cleaner and moister, but still much loaded. She had passed a better night, and without wandering.

Dec. 5th. Better on the whole; but the bowels were confined.

R Hyilraugyri chloridi gr. ij.

B Olei ricini $3 \mathrm{ij}$.

Cras mane.

Dec. 9th. Very much improred. To get up.

Dec. 14th. Tongue still cuuted, and bowels rather confined; motions dark and offensive. Repetatur hydrargyri chloridum and oleum ricini.

R Huustús salin. efferv. 弦,

Sextis horis.

Spiritús ætheris nitrosi 3 ss.

She now improved rapidly, and was perfectly convalescent by the 26 th.

CASE III. Emma B., aged 10. Feb. 7th, 1854. Was attacked on the 5th with rigors followed by heats, having been ailing for a few days previously. There was great prostration and languor; dry heat of skin; tongue dry and foul; pulse weak, 120 ; bowels regular. She wandered; but could always be roused sufficiently to answer questions.

B Liquoris ammonix acetatis $3 \mathrm{iij}$,

Spiritús ætheris nitrosi $\mathbf{j}$ ss,

Nisturæ camphoræ $3 \mathbf{v}$. M.

Fiat haustus quartis horis sumendus: 
Teb. 8th. No alteration in tho sgmptome

Iob. 8th Pulso 128; tongue dy and brom, with dew on teoth and lips; skin dry ; wes delirious at night, and wandered constantly during the day.

Feb. 10th. Much the same. Bowels regular; but motions were very dark coloured, and very offensive.

Hord noctis.

Feb. 11th. Bowels acted freely; and motions were much mare natural, though still very offensive.

Feb. 12th. Not quite so well; passed a restless night. Tangue more dry than yesterday; pulse 128.

B Olei ricini $3 \mathrm{ij}$.

Statim sumatur.

Feb. 13th. Very much better in every respect.

Feb. 17th. Greatly improved; but tongue still rather dry.

Feb. 18th. Tongue moist and cleaner; pulse 100, weak; bowels regular.

B Haustûs salin. ammoniæ effert. $\zeta$ j,

Spiritûs ætheris nitrosi 3 ss. M.

Fiat haustus sextis horis sumendus.

Feb. 20th. Was able to sit up; appetite returning. To hrve some meat.

Feb. 22nd. Still weak; but mending rapidly.

$R$ Infusi calumbæ $\jmath_{j}$,

Acidi sulphurici diluti p. M.

Fiat hanstns bis die sumendus.

Bhe continued to improze, and was out of my hands by the 25th March.

CONTINOED FEVER, AGGRATATED WITH COMPLICATIONS.

In these cases, we generally find the febrile attack of a more severe nature than the last; the complication not always showing itself at the first onset, but supervening afterwards during the progress of the disease. Sometimes, however, it does occur as one of the first, if not the very first, symptom to which the attention is directed. The observation I made with regard to the treatment of simple uncomplicated fever, will not hold good here ; inasmuch as, when a complication arises, it must be treated promptly, and with as much activity as the nature of the case will admit, remembering that the treatment must be modified by the complaint, which almost invariably has a tendency to a low form, and consequently will not admit of that amount of depletion which would be urgently required, if such a complication existed as a primary disease, independent of the fever with which it is now co-existent.

CASE IV. Emily J., aged 9. Oct. 26th, 1853. Suffering from severe diarrhcea of two days' standing, attended with much griping, but no sickness. Motions watery and inoffensive.

B Acidi nitrici diluti $m_{x} \mathbf{v}$,

Acidi sulphurici diluti $n \times$

Mistura acaciæ,

Aquæ menthæ piperitæ, āi

Fiat haustus quartis horis sumendus.

Three doses stopped the diarrhcea.

Oct. 28th. Had now well marked symptoms of continued fever. Pulse 120; tongue dry, dark, and loaded; skin dry and hot; wandered occasionally, but could always be roused; had cough, with slight mucous râle; bowels confined.

R Olei ricini $3 \mathrm{ij}$.

Statim sumatur.

B Vini ipecacuanhæe me

Spiritús ætheris nitrosi 3 ss

Liquoris ammoniæe acetatis $3 \mathrm{ij}$,

Nisturæ camphoræ 3 v. . M.

Fiat haustus sextis horis sumendus.

Oct. 30th. Much the same.

Oct. 31st. Pulse small and quick; tongue foul; wandered much at night; small crepitation at lower and posterior part of right lung. Repeat the mixture every four hours. A blister to be applied to the chest.

Nor. 1st. No change in the symptoms. To go on the ame.

Nor. 2nd. Small crepitation now extended nearly throughout the whole of both langs there was conniderable

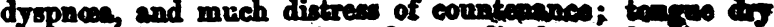

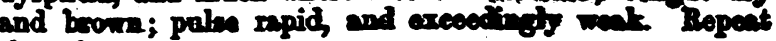
the mixture.

\section{Sextis horis.}

R. Hydrargari chloridi gr.j.

Nor. 3ed. Mucous rtle in upper lobes; small erepitation in lower. lobes of both lungs.

Nov. 4th. Small crepitation, now confined to lower lobe of right lung.

Nor. 5th. There was now no erepitation to be heard, and mucous rale was decreasing. She was much bettex in every respect; tongue cleaner; pulse 100. Leare of the powder, and repent the mixture.

Kov. 6th. Fespiration almost natural; and very mench improved in other respects. The mixture to be repentad every six hours.

Nov. 7th. Respiration natural; has scarcely any cough; pulse 80 , weak; tongue cleaning.

Nov. 8th. She had now no cough, and perspired a great. deal; tongue moist, and almost perfectly clean.

Nov. 9th.

$$
\begin{aligned}
& \text { B Infusi calumbs, } \\
& \text { Aqum menthæ piperite, sing. 3ss, } \\
& \text { Acidi sulphurici diluti 潒iij. II. }
\end{aligned}
$$

Fiat haustus ter die sumendus.

She now rapidly gained strength under the use of tonies, and was out of my hands by the 5th Dec.

In this case, the complication consisted of broncho-pnetmonia. Ioss of blood, however, under the circumstances, was totally inadmissible; but some active treatment was required. A blister was employed; but even this must, in such cases, be used with extreme caution. Calomel was of the utmost service; and, when its effects are carefully watched, the greatest benefit is often derived from its use, though the most disastrous consequences will sometimes ensue, if it be carelessly and indiscriminately administered.

Cass v. Henry R., aged 5. Dec. 5th, 1853. This child had three days before been taken with shivering, followed by heat, and had been very ill ever since; when seen he was feveriah with hot dry skin, tongue dry and brown, pulse 120; suffered much from thirst; wandered at night, and was peevish and restless by day; had cough with small crepitation in lower lobes of both lungs. Bowels regular, motions very offensive.

B Hydrargyri cum cretâ gx. iij.

Horâ noctis.

\section{B Haustûs salin. 3 ij,}

Vini ipecacusantse

Vini antimonii, ẩ $m \mathbf{x}$. M.

Fiat haustus quartis horis sumendus.

Dec. 6th. Better with regard to the chest symptoms, but wandered much at night. Bowels confined; tongue dry and brown. Repeat the mixture.

R Hydrargyri chloridi gr. j.

Hord noctis sumatur.

B Olei ricini $3 \mathbf{i j}$.

Cras mane sumatur.

Dec. 7th. Much the same.

Dec. 8th. Chest symptoms abating; no alteration in other respects.

Dec. 9th. Crepitation entirely gone, and was succeeded by mucous rale in larger bronchial tubes; still wandered at night; motions dark and very offensive; pulse rapid and weak; tongue foul but moist.

B Liquoris ammoniæ acetatis $3 \mathrm{ij}$,

Spiritús ætheris nitrosi $m=2 \nabla$

Vini ipecacuanha $m_{x}$,

Misturæ camphoræ 3 iv. M.

Fist hanstus sextis horis sumendus.

B Hydrargyri oum creth gr. ijj.

Hork noctis sumatur.

Dec. 10th. Much the same on the whole, but wanders. less at night.

Dec. 12th. Better in most reopeets; dept better; tompon

little clenner. To have noma ersemineot 
Dec. 14th. Improring; pulse weak and quick; tongue clemaer; bowels regular. To hare some weak beef tea.

Doc. 16th. Borels rolaxed; in every other respect better. Adde misture confectionis aromat. gr. XV sing. dos.

Dec. 17th. Bowels not so much relaxed; cough less; tongue clenner; pulse 84, reak.

Doc. 19th. Diarrhos had increased, but otherwise he was botter.

\section{R Misturre cretæ 3 ss,}

Confectionis aromat. gr. XV,

Tincture catechu m. M.

Fiat haustus quartis horis sumendus.

Dec. 21st. Diarrhoes had ceased, but cough was trouble. some.

\section{R Vini ipecacuanhæ $M x$, Oxymel. scillæ $m \times x v$, Misture camploræ $\overline{\text { ss. }}$ s.}

Fiat haustus sextis horis sumendus.

Dec. 23rd. Very much better. To get up.

Dec. 26th. Greatly improved, but was very weak, and :still had slight cough.

Bx Haustús salin. efferr. $\zeta i$, Vini ipecacuanhre $m x$.

Fiat haustus sextis horis sumendus.

Jan. 2nd. Had no cough; tongue perfectly clean; pulse weak; perspired a great deal.

B Infusi calumbæ Aquæ menthæ piperitæ, $\bar{a} \bar{a}$ 乡ss, Acidi sulphurici dilnti $\mathbf{p v}$. $M$.

Fiat hanstus ter die sumendus.

Jan. 11th. Able to go out, and was nearly well.

Jan. 18th. Very much better.

$\boldsymbol{B}_{\mathbf{x}}$ Vini ferri $3 i$.

Bis in die sumatur.

He now continued to improve, and was quite well by the 1st of February.

This was a delicate scrofulous child, and consequently much less depletion was required than in the last case: in fact, the same amount would have been injurious. Some caution is necessary in checking diarrhoea in these cases; it must not be allowed to proceed to a dangerous extent, but it certainly should not always be suddenly checked. I have seen such treatment, injudiciously employed, followed by fatal head symptoms.

Case vi. Emma C., aged 6. Feb. 10th, 1854. Had been taken ill on the 5th with sickness, headache, and shivering, and had steadily become worse; the tongue was dry and thichly coated; pulse 128, weak; skin hot and dry ; bowels regular; she complained of headache, and frequently wandered, more particularly at night, but could always be roused to answer questions coherently; there was cough. with dry rhonohus in larger bronchial tubes; respiration natural in other situations,

R Haustûs salin. efferv. Z $\mathrm{i}$,

Spiritús æetheris nitrosi $3 \mathrm{ss}$

Vini ipecactuanhæ $m_{\mathbf{x}}$. M.

Fiat haustus quartis horis sumendus.

Feb. 11th. Passed a restless night; in other respects much the same as yesterday.

Feb. 12th. Slept well during the night, but wandered a good deal when seen; the cough was rather more trouble;some, though looser; the rhonchus being replaced by slight mucous rale; pulse 128 ; tongue dry and brown; sordes on teeth and lips; bowels regular.

Feb. 13th. Passed a very bad night, raving incessantly, but was then much calmer and decidedly better than yesterday; the tongue, though thickly coated, was then moist; there was less sordes on teeth, and the lips were not so dry pulse 120, weak ; bowels regular, but motions dark-coloured and insuffersbly offensive; cough better. Repeat the mixture.

R. Hydrargyri cum cretâ gr. iij.

Hord noctis sumatur.

Feb. 14th. Had passed a rery bad night; tongue some- what more dry than the dey before, but lips and teeth cleaner; bowels had not acted that day.

Bx Olei ricini 3 ij.

Statim sumatur.

Feb. 15th. Slept better the night before, but became very restless towards morning, and had continued so; tongue foul and dry; pulse 120; bowels had acted twice freely; motions dark and offensive.

Feb. 16th. Rather more composed; tongue cleaner, but still very dry; pulse 120 .

Feb. 17th. Much the same as yesterday.

Feb. 18th. Had been quite delirious during the night, constantly raving and trying to get out of bed; there was, howerer, no heat of scalp, and she was then tolerably calm, and somewhat exhausted; pulse 120, exceedingly weak; lips cleaner; tongue dry and brown; bowels regular; motions less offensive; cough much better.

B. Haustûs salin. ammoniæ efferv. $z_{i}$, Spiritûs ætheris nitrosi $3 \mathrm{ss}$ Vini ipecactanhæ mvi. M.

Fiat haustus quartis horis sumendas.

Fab. 19th. Much the same, but weaker; to have some arrowroot.

Feb. 20th, 11 d.x. Had passed a very restless night, and taken to picking the bed-clothes; when seen the pulse was scarcely perceptible; she was languid, and could not be roused sufficiently to answer questions, or put out the tongue, which was dry and hard to the touch.

$B$ Vini rubri $3 \mathrm{ij}$.

Subinde sumatur.

4 P.x. Just as languid and imbecile as in the morning, but the pulse was a very little stronger.

Feb. 21st. Very much better; had passed a good night; could then be roused, and put out her tongue, which was quite moist and much cleaner; pulse 120, much stronger than yesterday, though still very weak; bowels had acted that morning, motions consistent, and not nearly so offensive as heretofore.

Feb. 22nd. Much the same as yesterday.

Feb. 23rd. Better; tongue moist and cleaning; pulse 100 , stronger. To hare a little fish.

Feb. 25th. Better in every respect; tongue perfectly clean; pulse weak. To have some soup.

B Infusi calumbr,

Aqux mentha piperitæ, ãñ $\breve{s s, ~}$

Spiritûs ammonia arom. mxr. $\mathbf{~ I I}$

Fiat haustus ter die sumendus.

March 3rd. Much better; pulse stronger; appetite improving.

March 8th. Was frightened last night by hearing some mice, and is now in a most distressing state of nervous excitcment. Adue misiura tincturæ nyusiywmi $\mathrm{m} \times \mathrm{x}$ sing. dos.

March 9th. Much better, and quite calm.

On the 17th she left off the henbane, and on the 29th took a drachm of steel wine three times a day; from this time she rapidly improved, and by the loth of April was perfectly well.

The chest symptoms in this case were not so alarming as in the two previous instances; simple bronchitis was present, but no pneumonia; the fever was very severe, and of a low form, and even the administration of antimony would have been prejudicial; ipecacuanha alone was required. In the majority of cases, depletion is not necessary ; such treatment would often be attended with serious consequences; even in cases of slight pneumonia, or bronchopneumonia, a combination of antimony with ipecacuanha in saline draught is all that is re puired to relieve the complication.

Case vir. Mary B., aged 5. Feb. 22nd, 1854. Had been attacked on the 18th with an epileptic fit, having been ailing for some days previously, and complaining of alternate chills and heats. The tongue was dry and brown; bewels confined; pulse 120, weak; skin hot and dry ' there was nausea, loss of appetite, much thirit, occasional wandering at night, 
and grent restlessness; she had been exposed to the contagion of continued fever, which had existed in the neighbourhood for some time past.

B Hydrargyri chloridi gr. j,

Pulveris jalapæ gr. ij. II.

Fist pulvis statim sumendus.

R Liquoris ammonixe acetatis $3 \mathbf{i j}$, Spiritús æetheris nitrosi $3 \mathrm{ss,}$

Nisture camplore 3 vi. A.

Fiat haustus sextis horis sumendus.

Feb. 23rd. Much the same as the day before; Dowels had acted freely; motions dark, and very offensive.

Feb. 24th. Complained of headache, and wandered morc at night; pulse 120 , very weak; tongue dry and brown; scalp hot. Head to be shaved, and cold vinegar and water spplied. Repeat the mixture and powder.

Feb. 25th. Somewhat better; passed a more quiet night ; bowels open, but motions dark and offensive.

Feb. 26th. Much worse; was delirious, and appeared in the greatest terror; a very small quantity of urinc had just been passed involuntarily, being the first roided for twentyfour hours; the bladder perfectly empty; tongue dry and brown; sordes on teeth and lips; pulse 120, exceedingly weak; bowels had not been opened.

$\mathrm{B}$ Olei ricini $5 \mathrm{ij.}$.

Feb. 27th. Much the same in most respects, but had cough with very slight mucous râle in larger bronchial tubes; still had delirium attended with terror. Repetatur mistura cum vini ipecacuanhæ mvi sing. dos. quartis horis.

Feb. 28th. Much worse; dreadfully terrified when roused, at other times almost totally insensible; cough much better; pulse 120, very weak; tongue almost black; teeth and lips covered with dry dark-coloured sordes; no great heat of scalp; very little water was passed, and only once in twentyfour hours.

March lst. Very much worse; was then almost totally insensible, but apparently sinking from downright exhaustion; motions pass involuntarily, and no more water is made than heretofore; pulse 120, and scarcely perceptible. Sumat rini rubri 3 ij subinde.

March 2nd. Quite insensible, and weaker than yesterday.

March 3rd. Was more restless, and much flushed; the hand was often raised to the head, which was exceedingly hot, though there was great general weakness. To leave off the port wine, and have three lecches to the temples.

March 4th. Very little if any relief from leeches; at present, 4 P.M., she was apparently dying, pupils dilated, and insensible to light, but motioned me away with her hand when touched; bronchial tubes clogged with mucus from inability to expel it.

R Decocti senegn 3 iv,

Spiritus atheris nitrosi,

Spiritús ammonice arom., àa $m x . " M$.

Fiat haustus quartis horis sumenclue.

His givie rëief, inasmuch as the mucus was at first coughed up and expelled, and subsequently passed into the pharynx and was swallowed, evidently affording great ease. She continued to sink, and died, without pain, at 3 A.M. on the 5th.

Post mortem examination. Body wellyormed, but somewhat emaciated.

Cranium. Dura mater healthy in structure, but sinuses and ressels congested; arachnoid contained in its cavity a considerable quantity of scrous fluid; veins on both hemispheres somewhat congested. On cutting into the brain, numerous bloody puncts were disclosed, and the grey substance was dark in colour; both lateral ventricles were much distended with scrum, though the septum lucidum was whole, firm, and healthy.

Thorax. The right lung was bound down by old pleuritic adhesions; upper lobes of both lungs studded with miliary tubercles; lower lobe of left lung congested, and mor righting lobe on right sepatized, and at its in fedor part presented a large cavity with loss of substance, but having no gangaepoug gdour or appearance of pus; a large bronchialramitication could be traced into it, thus accounting for the manner in which the coftened parenchyma was expelled. Heart healthy.

Abdomen. The peritoneum, and more particularly the great omentum, presented a singular appearance, being studded oper its whole surface with small mottled (black and whito) patches, looking like tubercular matter: these on microscopic examination by my friend Dr. Hare were proved to be nothing but deposits of fibrine; the intestines were all glued together by old adhesions, and the omentum was adherent to them throughout the whole of its posterior surface in a similar manner; kidneys large but healthy; other viscera natural.

CASE vili. Emma M., aged 3. Nor. Ioth, 1853. She had been seized two days previously with shivering, followed by heat; there was then great heat of skin, much thirst, and frequent vomiting; tongue foul and dry; pulse very rapid; bowels confined.

R Hydrargyri cum cretâ gr. ij.

Horâ noctis sumatur.

Bx Olei ricini 3 iss.

Cras mane sumatur.

R Liquoris ammonix acetatis 3 iss, Spiritûs ætheris nitrosi mxv, Misture camphoræ 3 iiss. $\mathrm{N}$

Fiat haustus sextis horis sumendus.

Nov. 18th. Much the same, and there was no material change until the 21 st, when I found that she had not made water for more than twenty-four hours; the bladder was not distended, but almost empty; she wandered occasionally, though there was no great heat of scalp, and there was constant sickness; bowels free; tongue dry and brown; pulse exceedingly wcak.

B Haustús salin. efferv. $̧$ i,

Spiritûs ætheris nitrosi 3 ss. M.

Fiat haustus quartis horis sumendus.

Nor. 22nd. Passed a small quantity of high-coloured acid water, soon after taking the first dose of the medicine, twenty-four hours before, but had made none since; she wandered more at night; motions dark, and very offensive.

R Hydrargyri cum cretá gr. iij.

Horâ noctis sumatur.

Nov. 23rd. Had once more made a very small quantity of water; bowels confined; pulse rapid, and very weak; could not be induced to take any nourishment. Ordered to have a little arrorroot occasionally.

R Olei ricini 3 ij.

Statim sumatur et repetatur si opus fuerit.

Nov. 24th. Had again passed one small quantity of water; bowels had acted comfortably after the medicine; pulse exceedingly weak; tongue dry and almost black; sordes on tecth and lips; she was frequently delirious and greatly terrified, but could always be roused, and appeared to be sinking irom exhaustion. Vini rubri $3 i$ subinde.

Nov. 25th. Much the same on the whole, but if anything a little better, and seemed revired by the wine. Still passed but one small quantity of urine in twenty-four hours.

Nov. 26th. Quite insensible; pupils fixed and dilated;

pulse scarcely perceptible, and far too weak to admit of plood; motions and uríne passed involuntarily, the latter still in small quantities, and at long intervals. Leave off the wine. Repeat mixturo.

R Hydrargyri chloridi gr. ss.

Secundis hotis.

Nor. 27th. Had had occasional convulsions, otherwise much the same.

Nov. 28th. Pulse hardly to be felt; still comatose, and appeared rapidly sinking; bronchial tubes filled with mucus, from inabiity to expel it. Intermittatur hydrargyri chloridi.

B Spiritûs ammaniz arom., Spiritús xtheris sulph. comp., ää $m x_{\text {, }}$ jisture camphore $\mathbf{j}^{\mathrm{iv}}$. $\mathbf{M}$.

Fiat haustus secundis horis sumendus.

Nor. 29th. Breathed more easily, the mucus being now expelled and swallowed : pupils fixed, dilated, and insensiblo 
to light and there were frequent and violent convulsions; she made more water, which, together with the fæces, passed involuntarily; bladder, as herotofore, quite empty.

Nor. 30th. Died. No examination of the body allowed. In both these cases, that peculiar delirium attended with terror (which I have once before mentioned) was present, and this was accompanied by a partial suppression of urine. I do not say that the circulation of urea in the blood was the cause of death in these cases; for in the first there was a great amount of fluid within the cranium, and in all probability the same appearance would have presented itself in the second child if an examination had been allowed; but still this symptom is importart, and I trust that the reiteration of my own remarks upon a previous occasion may not be considered improper, inasmuch as the symptom so frequently occurs with the suppression of this secretion. The delirium is of a peculiarly characteristic nature, and attended with great terror. "This state of horror is not unlike that which occurs in hydrophobia, though of course in a modified degree, and I have frequently noticed its appearance in children where there has been partial or complete suppression of urine, and urea conscquently circulating in the blood. The quality of the vital fluid is totally altered by the deleterious substance now contained in it, and irritation of the nervous system neces. sarily ensues; it is most certainly a very ominous symptom, and, as a general rule, we may look upon its appearance as a certain precursor of death." *

C.se IX. Elizabeth A., aged 10. Feb. 10th, 1854. Was attacked with shirering and heats on tire $6 \mathrm{th}$, since which time she had had sickness and headache, accompanied with dry heat of skin. For a month previously she had suffered from chorea affecting the right arm. Tongue dry and foul; pulse 120, weak; bowels open.

B Liquoris ammonire acetatis $\mathbf{j}^{\mathrm{iij}}$, Spiritús æetheris nitrosi $\bar{j} \mathrm{ss}$, Misture cemphore $j^{\mathrm{v}}$. M.

Fiat haustus sextis horis sumendus.

Feb. 11th. Just the same as the day before.

Feb. 12th. Pulse 128; tongue dry and coated; bowels confined. Passed a restless night, and wandered slightly. B Hydrargyri cum cretâ gr. iij.

Statim sumatur.

B Olei ricini $\mathbf{j} \mathbf{j j}$.

Post horas ij.

Feb. 13th. Bowels had acted freely; motions dark and cery offensive; tongue moister and cleaner; pulse 121. Passed a comfortable night, and appeared better.

Feb. 14th. Had passed a very restless night, and was then delirious, but could always be roused. There was tenderness on pressure over the whole abdomen. Tongue dry and brown, sordes on teeth and lips; pulse 132. Bowels had acted freely, but the motions had not been kept. She had a troublesome cough, with mucous expectoration. There was a mucous râle in larger bronchial tubes; otherwise the respiration was natural.

Applicatur cataplasma sinapis abdomini.

Bo Haustús salin. efferv. そ̧iss,

Vini ipecacuanhæ $m \mathbf{x}$,

Spiritús æetheris nitrosi jss. M.

Fiat haustus sextis horis sumencius.

Feb. 15th. Had passed a comfortable night, and was better in every respect. Cough diminished; no pain on pressing abdomen; motions loose, but less offensive, and of a better colour than before. Tongue moister; pulse 128.

Feb. 16th. Much the same.

Feb. 17th. Pulse 120, weak. Tongue and lips had been bleeding, and were then dry and dark from this cause, being coated with blood. Bowels regular; motions more natural; cough quite gone.

Bo Haustûs salin. ammonire efferv. $j_{j}$ Spiritûs ætheris nitrosi 3ss. II.

Fiat haustus sextis horis sumendus.

- On somo Anomalous Cases of Scarlatiua Lancet, March 25th, 1854 p. 827.
Feb. 18th. No return of bleeding; tongue moister and cleaner; pulse 120. Slept well during the night.

Feb. 20th. Puise 120; tongue cleaning; bowels regular; motions more natural.

Feb. 23rd. Pulse 120 ; tongue still rather dry, but cleaner. Suffered much from thirst.

Bo Haustûs salin. efferv. $\zeta$ iss, Spiritûs æetheris nitrosi 5 ss. Mr.

Fint haustus sextis horis sumendus.

Feb. 27th. Improving rapidly; tongue perfectly clean; pulse $1(10$.

B. Infusi calumlix, Aquæ menthit: piperite, sing. $\zeta$ ss,

Spiritûs ammonic aronntici mxv. M.

Fint haustus ter die sumendus.

March 1st. Nuch better, and totally frec from any sign of chorea.

March 7 th. Was attacked the previous night with serere ear-ache, followed that morning by a frce discharge of healthy pus, giving relief to the pain. Ear to be bathed with tepid water.

March 8th. Therc was considerable pain in the ear, and copious discharge. A small blister was ordered to be placed behind it.

March 10th. Pain quite relieved, and scarcely any discharge.

The discharge of pus soon ceased, and was not followed by any deafness. On the 27 th she began to take steel wine, and was perfectly well by the 24 th of $A$ pril.

Her brother, aged six, suffered from the simple uncomplicated form of ferer. The attack was slight, and commenced at the same time as his sister's. He passed through the complaint without any peculiarity worthy of notice. The ferer was introduced into the house by a relation who came to stay with them, she being at the time affected with it. The mother had it subsequently, and then the two children.

\section{COYTINUED FEVER, COMMANCING IN TIIE FIRST ISSTANCE} WITH REMITTEXT SYMPTONS.

This form of fever is, I beliere, almost peculiar to children. The patient appears ill, is affected with a peculiar malaise (to use the French term, for which we have no expressive translation), and, at the first onset, it is extremcly difficult to say what the real nature of the case is. Soon, however, we find irregular febrile symptoms set up; there are slight periodical exacerbations, often with perfect intervening remissions, during which times little or no signs of illness are apparent; the exacerbations then become longer in duration, and more severe in their character; the remissions are not attended with the same freedom from uneasiness as heretofore; they become shorter and shorter, until they ccase altogether, and the fever assumes the true continued form. It is not always that we are called in at the commencement of the attack; it often appears so trifling, and passes so gradually into the later stage, that medical advice is more generally sought when it has arrived at this point, and there can be no mistake as to its real nature. It is important, however, to ascertain the pre-cxistence of the symptoms alove mentioned; for they may have existed some little time before the outbreak of the unmasked disease, slowly and insidiously enervating the patient, and lowering the vital powers, which hare still to be sorely taxed by a long and tedious illncss. In all such cases, convalescence is protracted; the complaint is always severe, almost invariably of a low form, and frequently attended with dangerous complications; and, when the acute febrile attack, and such complications as may have attended it, have subsided, we find a state of debility and emaciation remaining, in many cases truly awful to behold, and a train of symptoms ensuing which require the greatest possible care and attention to combat. The acute stage has passed, but the poisonous miasma has not/ left the patient; the symptoms, previously of a lowizin now assume eren a lower type; and, knowing this to be the case, it will behore us to be exceedingly cautious with re- 
and to depletion, should we bo obliged to have recourse to It for the trentment of any complication which may arith in the last stage. The ferer which now exists is comenhat of a hectic character; there are frequently the low nocturnal exacerbations, followed by profuse debilithing perspirations; there is a total loss of appetite, languor, and, where the patient is old enough to have any ideas upon the subject, a strange indifference as to the result; even in very young children there is a state of apathy answering to this, which must strike every one who closely watches the case. I more particularly advert to this last symptom as a prognostic sign; for, bad though the case may be, so sure as ever we find this state of indifference passing off, or the younger child becoming more lively, and taking interest in the objects around it, we may have hope, aye, and strong hope, that recovery will take place. Then once the symptoms begin to abate, the patient progresses slowly but surely to a state of health, though it is always a considerable time before this happy condition is arrived at. This form of continued ferer, then, may be divided into three stages: first, the remittent stage; secondly, the continued stage; thirdly, the hectic stage. The child having passed through the two first stages of the complaint, the most anxious time arrives; support is required; but the greatest possible caution is necesport is required; beating the patient, and perhaps thereby inducing some low form of inflammation, which would be difficult or probably impossible to control under such circumstances. We must carefully watch the case, cautiously administering such remedies as may be necessary, and increasing or diminishing the amount of nourishment, until the time comes when we can with impunity push on our nutritive and tonic treatment; when, in fact, all serious anxiety as to the future progress of the disease has ceased, or, to speak more plainly, when nothing but debility is left as a sequel.

Case X. George B., aged \&. January 4th, 1854. He had been suffering for several days from well marked symptoms of remittent fever, with distinct exacerbations cvery evening and much nausea and headache. There was then great languor, excessive thirst, and dry heat of skin; cough with dry rhonchus in larger bronchial tubes. Tongue dry and brown; lips parched and cracked; pulse 128, weak; bowels regular, but motions very offensive.

Bo Hydrargyri cum cretâ gr. iv.

Horâ noctis sumatur.

B. Liquoris ammonix acetatis $3 \mathrm{ij}$,

Spiritûs ætheris nitrosi 3 ss,

Vini ipecacuanhæ $m x$,

Nisturæ camphoræ 3 vi. $\mathbf{~ I}$.

Fiat haustus quartis horis sumendus.

Jan. 5th. Much the same.

Jan. 6th. Cough looser; dry rhonchus succeeded by mucous ralc; pulse 120; tongue dry and brown; bowels confined.

$$
\text { Bo Olei ricini } 3 \mathrm{ij} \text {. }
$$

Statim sumatur.

Jan. 7th. Tongue moister, but still very foul ; the bowels have acted freely; pulse 128, weak; cough, the same.

Jan. 8th. Wandered the night before, but was then quite rational ; tongue more dry; otherwise much the same.

Jan. 9th. Had passed a restless night, and was somewhat incoherent, but could always be roused sufficiently to answer questions. Was still troubled with cough; bowels open, motions dark and offensive; tongue dry and brown, with sordes on teeth and lips; pulse 128 .

Bo Hydrargyri cum cretâ gr. iij.

Horâ noctis sumatur.

Jan. 10th. Much better; tongue cleaner and moister; motions less offensive and of a better colour; was more calm and had passed a good night.

Jan. 12th. Very much reliered as to the febrile symptoms, but still troubled with cough.

Jan. 14th. Continued to improve; slept well and was perfectly rational, but had no appetite, and was still troubled with dry harsh cough; tongue cleaner; pulse 120.

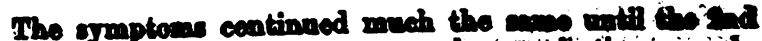

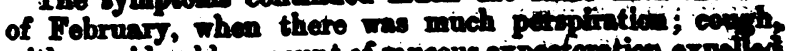
with considarable smount of mucous expectorition expalia with difficulty; no appetite, and great ensciation; tongue tolerably clean; pulso reak.

B Hrustús salin. efierv. $\zeta^{i}$,

Vini ipecacuanhæ $m \times$. M.

Fiat baustus quartis horis sumendus.

Feb. 10th. Somewhat better, but had no eppetite; congh much the same, expectoration more free.

B Haustus salin. ammonix efferv. $3 i$, Vini ipecacuanhæ $m x$. M.

Fiat hanstus quartis horis sumendus.

Feb. 13th. Very weak and thin; still without appetite; tongue clean; cough a little better.

Bo Infusi calumbr, Aquæ menthæ piperite, sing. $\xi s s$, Oxymel. scills 3 ss. M.

Fiat haustus ter die sumendns.

Feb. 15th. Much the same; bowels confined.

B Olei ricini $3 \mathbf{i j}$.

Statim sumatur.

Feb. 18th. Much weaker and thinner; cough much the same; to have two ounces of port wine daily.

Feb. 20th. Thinner, weaker, and no appetite.

Feb. 22nd. Dreadfully emaciated; languid and unwilling. to be moved; complained of much pain in his limbs, and cried on being touched.

Feb. 24th, Cough worse, and attended with profuse expectoration.

Bo Tincture benzoini comp. $m \times v$,

Tincturæ camphoræ comp. $3 \mathrm{ss}$,

Misturæ acaciæ $3 \mathbf{i}$,

Vini ipecacuanhæ $m v i$,

Misturæ camphoræ 3 vi. M.

Fiat haustus ter die sumendus.

Feb. 26th. Much weaker; cough the same.

B Decocti senegæ,

Haustûs cinchonæ, sing. そ̌ss. M.

Fiat haustûs ter die sumendus.

Feb. 28th. Getting weaker and weaker; emaciation perfectly dreadful to look at; tongue dry, red, and glazed; pulse scarcely perceptible. Adde misturre spiritûs ammoniæe aromat., et spiritâs ætheris sulph. comp., ā mxx, sing: dos.

March 2nd. A little better if anything.

March 4th. Appeared sinking; was still dreadfully troubled with cough, but there was evidently no deposition of tubercles or vomice, the stethoscopic signs showing that. chronic bronchitis alone existed. The skin over the right. trochanter was beginning to slough; soap plaister to be placed over it. To take port wine almost ad libitum.

March 6th. Somewhat better; skin over trochanter more healthy in appearance and inclined to heal.

Bo Olei jecoris aselli $j^{i j}$.

Ter die sumatur.

March 7th. Is now suffering from violent diarrhœea.

Bo Decocti hæmatoxyli $\xi^{i}$, Tincturæ opii miv. $\mathbf{l l}$.

Fiat haustus quartis horis sumendus.

March 8th. Diarrhcea has quite ceased, and the child. seemed a little better.

Bo Quinæ disulphatis gr. ij, Acidi sulphurici diluti $\mathrm{m} \mathbf{v}$, Aquæ $3 \mathrm{i}$. M.

Fiat haustus ter die sumendus.

March 10th. Appetite returning; tongue more healthy in appearance; to have beer and anything he fancied to eat; as well as two ounces of port wine every day. He now continued to improve up to the 15th, when his tongue was red and raw, but moist; cough much better, and expectoration less.

Bo Mistare ferri comp. 3 i.

Ter die sumatur. 


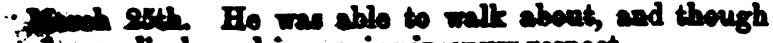

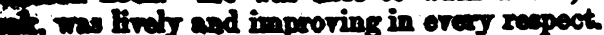

Minol soth He could $g^{\circ}$ out; and from that time he procressed rapidly up to the 24th $\Delta$ pril, when he was perfectly well and hearty.

Casn xI. Gertrude W., aged 7. Jan. 25th, 1854. She had mefered for the previous four days with well-marked remittent symptoms, which were then succeeded by continued fover; she had severe headache, and intolerance of light; nawees; loss of appetite, and thirst; there was dryness of skin; tongue foul and dry; pulse 120; bowels confined.

B Liquoris ammoniæ acetatis $3 \mathrm{z}_{\mathrm{j}}$ Spiritús ætheris nitrosi 3 ss Misture eamphore $3^{\text {vi. M. }}$.

Fiat haustus sextis horis sumendus.

Bo Hydrargyri cum cretâ gr. ijj.

Horâ noctis sumstur.

B Olei ricini $3 \mathrm{ij}$.

Cras mane sumatur.

Jan. 26th. She passed an uneasy night, but did not wander ; head less painful; bowels had acted from medicine, motions dark and offensive; pulse 120; tongue very foul but a little more moist.

Jan. 27th. Much the same as yesterday.

Jan. 28th. Wandered a good deal during the night, but was then quite rational ; tongue dry and brown; complained much of her head, and there was great intolerance of light; pulse 128. Repetantur pulvis et oleum ricini.

Jan. 29th. Bowels had been relieved, motions very offensive; tongue not quite so dry; less headache; pulse 128; had passed a better night.

Jan. 30th. Had been delirious during the night, and wandered when seen, but could be roused to answer questions; pulse 132; tongue dry and brown; sordes on teeth and lips, bowels confined.

B Haustûs salin. efferv. $j_{\text {, }}$ Spiritûs ætheris nitrosi §ss. Mr.

Fiat haustus quartis horis sumendus.

Bo Hydrargyri chloridi gr. j, Pulveris jalapæ gr. viij. $M$.

Fiat palvis statim sumendus.

Jan. 31st. Passed a very restless night, constantly wandering, and was much in the same state when seen; bowels had acted freely, motions dark and offensive; pulse 132; tongue almost black.

Feb. 1st. No alteration in the symptoms since yesterday, with the exception of the bowels not acting.

Bo Hydrargyri chloridi gr. ij.

Statim sumatur.

Bo Olei ricini 3 ij.

Post horas ij sumatur.

Feb. 2nd. Slept a little during the night, and was much calmer; tongue not quite so dark but still dry and brown; bowels relieved by the medicine; pulse 128 .

Feb. 3rd. Worse, and constantly wandering; tongue dry and brown; pulse 132; bowels had not acted since yesterday. To repeat the calomel and oil.

Feb. 4th. Bowels had acted freely, and she was now much better; pulse 120 ; tongue very foul but becoming moist.

Feb. 5th. Passed a comfortable night, and was better in every respect.

Feb. 6th. Tongue moister and cleaner; pulse 120, weak; bowels regular.

She now gradually improved, as far as the acute febrile symptoms were concerved, until the 27 th, when she was dreadfully emaciated, and had no appetite; the tongue, however, was nearly clean; pulse 100, weak; and there was slight cough without any stethoscopic signs.

Bo Haustús salin. ammonire efferv. $\zeta_{j}$, Spiritûs æetheris nitrosi 3 ss,

Vini ipecacuanhæ $m$ vi. M.

Fiat haustus quartis horis sumendus.

March 1st. Much the same.

March 6th. Dreadfully emaciated, and no return of appetite; tongue nearly cleau; pulse 100; bowels regular.
March 15th. Tongre perfoctly clean; pulse 80, weak; appetite returning.

B Olei jocoris aselli jij.

Ter die sumatur.

March 22nd. Very much improved and beginning to gain flesh.

B Olei jecoris aselli $\zeta$ ss.

Ter die sumatur.

March 24th. She now continued to improve, and under the use of tonics, wine, and good food, completely recovered her health and strength.

CASE xII. William R., aged 3. Dec. 19th, 1853. Was attacked a week previously with remittent ferer, which had gradually assumed the continued form; there was then great prostration; constant wandering at night, and occasionally in the day time, but he could always be roused sufficiently. to answer questions; there was cough with mucous rile in upper lobes of both lungs; skin hot without perspiration; tongue brown and dry; pulse 140, weak; bowels confined.

Bo Haustús salin. jojij,

Vini ipecactuanhæ,

Vini antimonii, sing. $m x$. M.

Fiat haustus sextis horis sumendus.

B Hydrargyii chloridi gr. ij.

Horâ noctis sumatur.

B Olei ricini $3 i j$.

Cras mane sumatur.

Dec. 20th. Much the same.

Dec. 21st. Still wandered at night; chest symptoms just the same; skin dry ; tongue brown; pulse 120 ; bowels very much confined. Adde misturæ spiritûs ætheris nitrosi jss, misturæ camphoræ $3 \mathrm{ij}$, sing. dos.

Bo Hydrargyri chloridi gr. i, Pulveris jalape gr. vi. M.

Fiat pulvis statim sumendus.

Dec. 22nd. Bowels had acted freely, motions very offensive; wandered less at night; tongue cleaner but still dry; mucous râle much less and entirely confined to large bronchial tubes.

Dec. 23rd. Much better; slept well last night; chest symptoms almost entirely relieved; tongue coated, but becoming moist.

B. Haustus salin. efferv. $3 . j$,
Vini ipecacuanhe mx. M.

Fiat haustus quartis horis sumendus.

Dec. 28th. Much better, but had no appetite.

Jan. 2nd, 185̄. Improving rapidly.

Jan. 6th. Appetite returning, but still has slight cough.

Jan. 9th. Very much better; tongue clean; bowels regular ; cough almost gone.

Bo Infusi calumbr, Aqua mentha piperita, sing. zss, Oxymel. scilla jos. M.

Fiat haustus ter die sumendus.

Jan. 11th. Was feverish from medicine. To leare off the mixture, and take the effervescing saline again.

Jan. 16th. Still a good deal of cough, particularly at night; in other respects better.

Jan. 20th. Small crepitation in lower lobe of right lung, and considerable difficulty of breathing. Mustard poultice to the chest.

\section{Bo Haustûs salin. $\mathbf{j}^{\mathrm{ij}}$,}

Vini antimonii potassio-turtratis,

Vini ipecacuanha, sing., $\mathrm{mx}$. Mi.

Fiat haustus quartis horis sumendus.

B. Hydrargari chloridi gr. $i$.

Omni nocte et mane sumatur.

The mother of the child now put him under the care of $\mathrm{s}$ general practitioner in the neighbourhood, imagining that he would get better if she paid for his treatment; and I subsequently learned the following particulars. When I supposed the child to be feverish from the medicine, his mother was dosing him with bad port wine unknown to me, 
and with this she perserered until she remored him from nider my care. She then never said a rond about the mier my care. She then her own stimulating treatment, though no doubt she continued it. In a short time she became tired of paying, and took the child to a physician, under whom he died on the 15th of March.

REMarrs. The term " continued fever" has often been objected to, at least in a comprehensive sense; nevertheless, until some really better term can be invented, I am perfectly content to retain it. If we refer to Dr. Watson's Lectures on the Practice of Physic-which, though a text-bouk for students, may with the greatest advantage be referred to at any time by the busy practitioner in his moments of leisure-we find the following passage:- "And systematic writers are to the full as particular: mucous fever, ataxic, adynamic, gastro-enteritic, and so forth. Now, admitting that fever shows itself under various forms, I am persuaded that the effect upon the mind of all this subdivision is bad and hurtful. It encourages a disposition, already too prevalent, to prescribe for a disease according to its name. There is no line of genuine distinction between continued fevers that can be relied on; they run insensibly into each other, even the most dissimilar of them; and are traceable often to the same contagion." In this opinion 1 perfectly agree; but if we go back to a much higher opinion than my poor humble self, and look to Cullen, we find him describing his synocha and typhus as two distinct forms, and then comes his synochus: "Febris ex synochâ et typho composita: initio synocha, progressu et versus finem typhus." Now, does not this great observer of nature, by this very description, admit the fact that the genuine types of disease are the exceptions, and that the anomalous cases, as they may be termed, are the general rules; that we seldom if ever meet with a complaint of any sort running the uninterrupted course so pleasantly and beautifully described in books? Even in the few cases brought forward in this paper, various subtle subdivisions might be made; but they are all of one class, the only difference being in the systcm of the individual affected by them: thus, from George B., Case I of my third subdivision, we have Emma B., Case III of my first, taking a totally different form of complaint. They were brother and sister, living in the same room; and in each the disease assumed a dissimilar form. In the last subdivision I have made use several times of the term "remittent fever", and perhaps inappropriately, at least with regard to the diseases of children; but the words have been employed in deference to common usage, and merely in allusion to certain appearances occurring in the course of the cases related. Infantile remittent fever, as commonly described, is certainly not a disease per se; it is but a symptom, and, if otherwise regarded, is likely to lead to fallacies which must have a pernicious effect. Do not the peculiar symptoms in the so-called "remittent fevers" depend upon gastro-enteritic irritation? and do they not in all cases cease, or do they ever cease (unless further mischief occurs), until this irritation is removed? In what manner do they differ as a symptom from the typhoid fever in cases of diffuse cellular inflammation, or the hectic ferer present in phthisis? As well might the surgeon treat the typhoid symptoms alone, and neglect the local cause, or the physician forget the pulmonary disease, and give his sole care to the hectic symptoms, as the child's attendant give up his entire notice to the remittent symptoms, carelessly neglecting the fact that the cause is still remaining.

"Whut's in a name? That which we call a rose,

13y any other nane would smell as sweet."

From this sentiment of our immortal poet I most presumptuously beg to differ; for, without doubt, much mischief may arise from a name misapplied.

16 Welbeck Strcet, Carcudish Square, June 1st, 1851.

\section{CASES ILLUSTRATING THE ADVANTAGHS DERIVABLE FROM THE USE OF THE OPHTHALMOSCOPE.}

\section{By J. W. HULKE, Esq., Medical Tutor in King's College, London.}

THs subjoined cases are in some measure illustrative of the advantages to be derived from the ophthalmoscope: they show the assistance it affords us in obtaining a correct. knowledge of the condition of the parts concerned in many/ obscure affections of the eye.

Some of these cases are examples of musca votitantes depending on the presence of opaque particles in the vitreous humour, or caused by changes in certain parts of the retina; frequently both causes occur simultaneously. There are one or two cases of amaurosis where the retina was found separated from the choroid and raised into a cyst; and one case where the diagnosis was doubtful, but in which opacity of the lens was detected when the ophthalmoscope was used.

Case 1. Ayaurosis with Musce Vouitantes hike. TANGLED WooI. I. S., a militia-man, applied, last May, to Mr. Bowman for impaired vision of the right eye. He said that he saw two large black spots moring about; they were like tangled wool, and of the size of a fourpenny-piece.

Examination with the Oplethalmoscope. The upper part. of the retina seemed healthy; the vessels were enlarged at. the lower part, where there was some grey flocculent matter, which changed its place with erery movement of the ejeball.

Case if. Amatrosis witir Musce. J. B., aged 44, a. messenger, applied last January for dimness of sight of both eyes and muscæ. In October last, he had primary syphilis, which was followed in November by a rash and sore throat. In December, the sight of the left eye became impaired; he says that the eye looked like a ball of blood, but that he was not in pain. He saw things like black peas floating about.

Examination with the Oplithalmoscope. Black bodies, resembling coarse grains of gunpowder strung together in threads, were seen floating in the left vitreous humour.

CASE III. AMAOROSIS AND MUSC. J. J. F, aged 29 , applied in the beginning of June at King's College Hospital, for dimness of sight. A fortnight before, she had had a violent sick headache, and directly afterwards her sight became dim. During the week preceding her application, she suffered from a dull aching pain in the back of the. right eyeball; and four days before application she first noticed a cloud hovering over anything she looked at. On the preceding night she was awakened by a most intense pain in the eye. She saw imperfectly by day and hardly at all by candle light. The muscr were dark bodies grouped together in the form of a cloud. The pupil was ratherlarge, but active.

Examination with the Ophthalmoscope. There were several dark bodies floating in the vitreous humour; they changed their position as the eye was moved about.

This woman has been greatly benefited by bichloride of mercury; the muscæ have become fewer, and the cloudless opaque.

Cabe iv. Amaurosis: Opaque Particheg ln Vitreoug Humour Not PRODUCING MUsc.s. J. N., aged 32, a cabinet. maker, had always had fair sight until a fortnight before application. For the last six months, he had been in the habit of drinking to excess, and he had found the sight of both his eyes impaired after these drinking bouts; but for the last fortuight he had only been able to read the names: over shopfronts.

Examination with the Ophthalmoscope. Left Eye. The retina could hardly be seen through the vitreous humour, which was filled with small black bodies, some of which resemble threads. Similar appearances presented themselves. in the right eye.

Case v. Concussion of tile Braix, rollowed bY EPTLEPST AND AMAC ROSIS. R. W., aged 48, a mail-cart driver, applied, last June, to Mr. Bowman for impaired sight of 